\title{
RESPIRAÇÃO DO SOLO COMO BIOINDICADOR EM ÁREAS DEGRADADAS
}

\section{SOIL RESPIRATION AS BIOINDICATOR IN DEGRADED AREAS}

\author{
Carla Maria Abido Valentini \\ Instituto Federal de Educação, Ciência e Tecnologia de Mato Grosso - IFMT \\ Joadil Gonçalves de Abreu \\ Universidade Federal de Mato Grosso - UFMT \\ Rozilaine Aparecida Pelegrine Gomes de Faria \\ Instituto Federal de Educação, Ciência e Tecnologia de Mato Grosso - IFMT
}

\section{RESUMO}

A respiração do solo é um dos parâmetros mais empregados para quantificar a atividade microbiana, podendo ser utilizado como biodindicador de mudanças na dinâmica do carbono do solo em áreas que sofreram alterações na sua cobertura, como o desmatamento. O objetivo deste trabalho foi avaliar a recuperação de uma área degradada, usando a respiração do solo determinada pelo método químico de armadilha de álcalis $(\mathrm{KOH})$ e a análise química por titrimetria com solução aquosa de $\mathrm{HCl}$. Para isso, foram selecionadas duas áreas, uma revegetada com espécies do Cerrado e outra antropizada, distantes entre si em 220m, no município de Cuiabá-MT. As coletas foram realizadas mensalmente no período de julho de 2012 a junho de 2013, com exposição da armadilha de álcalis por 24 horas. De acordo com resultados, a respiração do solo na área revegetada foi maior que na área antropizada em todos os meses. $\mathrm{Na}$ área revegetada houve correlação significativa entre a respiração do solo e temperatura do solo $(r=-0,54)$, entre a respiração do solo e a umidade do solo $(r=0,67)$ e entre a respiração do solo e a precipitação $(r=0,62)$. Na área antropizada, as correlações entre a respiração do solo e os fatores abióticos não foram significativas. Concluiu-se que a revegetação foi determinante para o estabelecimento da comunidade da fauna do solo, visto que o material vegetal nesta área foi responsável pelo quantitativo de $\mathrm{CO}_{2}$ produzido durante o ano, em média, 1,5 vezes maior, que na área antropizada.

Palavras-chave: efluxo de $\mathrm{CO}_{2}$ no solo; armadilha de álcalis; áreas revegetadas.

\section{ABSTRACT}

Soil respiration is one of the parameters more employed to quantify the microbial activity and it have been used as bioindicator of changes in soil carbon dynamics in areas that have changed land cover, such as deforestation. The objective of this study was to evaluate the recovery of a degraded area, using the soil respiration determined by the chemical method of alkali trap $(\mathrm{KOH})$ and chemical analysis by titrimetry with aqueous $\mathrm{HCl}$. For this, two areas were selected, one revegetated with Cerrado species and other anthropic, distanced from each other at $220 \mathrm{~m}$, in the city of Cuiaba-MT. Samples were collected monthly from July 2012 to June 2013, exposing the alkali trap for 24 hours. According to results, the soil respiration in revegetated area was higher 
than the anthropic area every month. In revegetated area was significant correlation between soil respiration, soil temperature $(r=-0.54)$ and between the soil respiration and soil moisture $(r=0.67)$ and between soil respiration and precipitation $(r=0.62)$. In the anthropic area, the correlations between soil respiration and abiotic factors were not significant. We can conclude that the revegetation was crucial to the establishment of soil fauna community since the plant material in this area was responsible for the quantity of $\mathrm{CO}_{2}$ produced over a year on average, 1.5 times higher than the anthropic area.

Keywords: $\mathrm{CO}_{2}$ efflux in the soil; alkali trap; revegetated areas.

\section{INTRODUÇÃO}

As alterações dos Biomas pela ação humana modificam os ciclos do carbono e nitrogênio, elementos importantes para manutenção da dinâmica dos ecossistemas e torna-se importante se desenvolver estratégias de manejo que visem a preservação de áreas não antropizadas e a recuperação de áreas degradadas (MOREIRA, 2013).

A substituição da cobertura vegetal e práticas de preparo do solo influenciam diretamente no estoque de carbono por alterar a taxa de adição e de decomposição da matéria orgânica do solo (POST \& KWON, 2000).

O carbono constitui cerca de $56 \%$ da matéria orgânica do solo e cerca de $45 \%$ do tecido vegetal. Segundo Houghton (2001), o estoque de carbono orgânico nos solos, em torno de 1,5 a $2 \mathrm{Pg}$, é cerca de duas vezes maior que o estoque de carbono na atmosfera e cerca de três vezes maior que todo o carbono contido na biomassa vegetal do planeta.

Os teores médios de carbono nas espécies do Cerrado são $43,24 \%$ na folhagem, $42,06 \%$ nos galhos, $40,09 \%$ nas raízes, $41,01 \%$ nos fustes e $40,60 \%$ nas cascas (VIEIRA et al., 2009).

Práticas que contribuem para a adição, ou remoção de material vegetal do solo, acarretam alterações na biomassa microbiana, as quais podem ser avaliadas pelos quantitativos de gás carbônico produzido (SILVA et al., 2010).

Para quantificar a atividade microbiana, um dos mais antigos parâmetros é a respiração do solo e pode ser utilizada para se documentar mudanças na dinâmica do carbono do solo em áreas que sofreram desmatamento para implantação de culturas (FEIGL et al., 1995).

A respiração do solo ou edáfica pode ser definida como a produção de $\mathrm{CO}_{2}$, ou consumo de $\mathrm{O}_{2}$, como resultado de processos metabólicos de 
organismos vivos do solo, mostrando algumas etapas de maior vigência no processo de decomposição da matéria orgânica e reflete a redução de carbono pelo sistema solo e a reciclagem de nutrientes (PARKIN et al., 1996).

A saída do gás carbônico para a atmosfera, resultante desses vários processos que ocorrem na serrapilheira, na superfície e nas camadas mais profundas do solo, é chamada de efluxo de $\mathrm{CO}_{2}$ e pode ser medida por métodos de covariância por vórtice turbulento, por uso de por infravermelho (IRGAs) em câmaras fechadas (DAVIDSON et al., 2002), ou ainda por métodos químicos baseados na absorção de $\mathrm{CO}_{2}$ usando solução álcali (GRISI, 1978). No entanto é difícil atingir um valor preciso devido às incertezas associadas dos vários métodos e a grande variedade espacial e temporal inerente à respiração do solo e fatores ambientais (NORMAN et al., 1997).

A velocidade dessa liberação de carbono vai depender de fatores bióticos (microrganismos do solo) e abióticos (umidade, temperatura), assim, qualquer fator que altere as condições microclimáticas do solo e sua interface com a atmosfera pode afetar a taxa de respiração e o balanço de carbono em escala local e regional.

No município de Cuiabá, no perímetro urbano, uma área $144.000 \mathrm{~m}^{2}$ do Parque Estadual Massairo Okamura, ainda como Reserva Ecológica, em 1989, foi cedida pelo Governo do Estado à Escola Técnica Federal de Mato Grosso (ETF-MT), hoje IFMT campus Cuiabá-Bela Vista (CAMPOS \& SILVA, 1998). Parte da sua cobertura vegetal original do Cerrado foi perdida em função das obras realizadas pela instituição, porém há duas décadas, uma área foi isolada no campus e houve a sua revegetação com espécies do mesmo bioma, cujo bosque já está em processo de estabilização.

O mais importante, porém, é verificar a manutenção das funções do ecossistema, independentemente do estágio de equilíbrio atingido (MORAES, CAMPELLO \& FRANCO, 2010). A escolha de parâmetros que possam funcionar como indicador ecológico está baseada na comparação entres sítios onde houve distúrbios e outros mais bem conservados, que possam funcionar como referências para estudos comparativos (GROOFFMAN et al., 2001). Além disso, o indicador selecionado deve ser claramente definido, a fim de evitar confusões no seu desenvolvimento ou interpretação, ser prático e realista, o que supõe levar em consideração o seu custo de coleta, ser de alta 
qualidade e confiabilidade, e ser usado nas escalas espacial e temporal adequadas (MANOLIADIS, 2002).

Baseado nessas informações, o objetivo deste trabalho foi avaliar a importância da recuperação desta área com revegetação em relação a uma área antropizada distantes entre si em 220 m, usando como parâmetro bioindicador a respiração do solo medida por método químico de armadilha de álcalis.

\section{MATERIAL E MÉTODOS}

\section{Local do estudo}

O estudo foi realizado em duas áreas: uma área revegetada com espécies do Cerrado que chamaremos de bosque e uma área antropizada, distantes entre si em 220 m, ambas inseridas do Parque Estadual Massairo Okamura cedidas ao Instituto Federal de Mato Grosso- Campus Cuiabá-Bela Vista (coordenada de referência 15³4'45,02"S e 5603'45,78"O, altitude 207m), no município de Cuiabá-MT, conforme ilustra Figura 1.

Figura 1. Localização das áreas em estudo: área revegetada com espécies do Cerrado (bosque) e área antropizada.

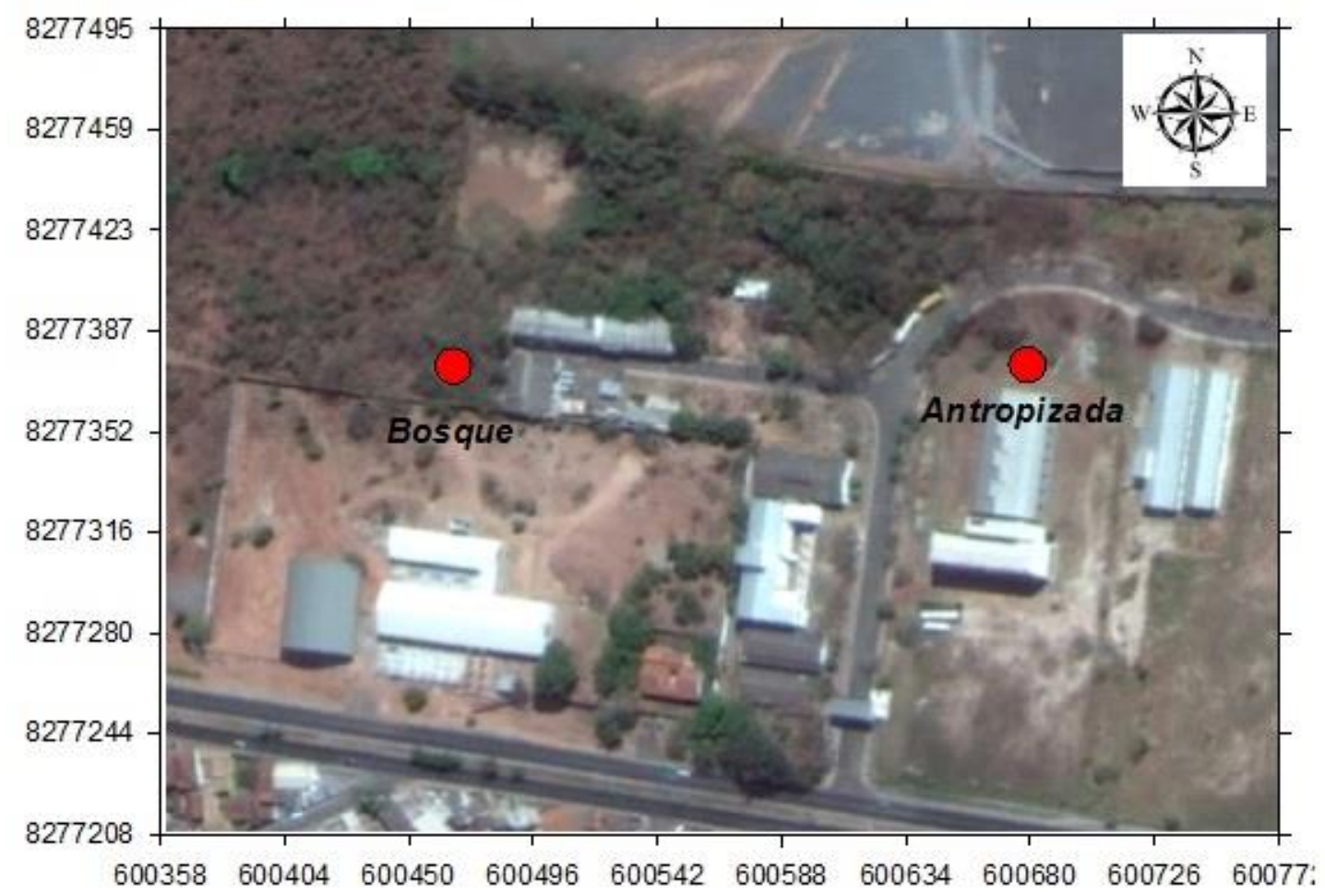


Fonte: Imagem: Googleearth, Digital Globe 2015. Unidade em Universal Transversa de Mercator - UTM.

O bosque possui espécies de Cerrado, e conforme levantamento florístico realizado nessa área foram amostrados 181 indivíduos, 18 famílias botânicas e 32 espécies, sendo as famílias mais comuns: Anacardiaceae, Rubiaceae e Fabaceae. As espécies mais importantes são: Jacaranda cuspidifolia, Anadenanthera macrocarpa, Myracroduon urundeuva, Curatella americana e Astronum fraxinifolium com $63 \%$ dos valores de abundância (MORAIS, VALENTINI \& CORREA, 2014). A segunda área é antropizada com retirada de vegetação e revolvimento do solo e localiza-se ao lado da quadra de esportes do campus.

Conforme classificação climática de Köppen, o clima de Cuiabá é Aw, ou seja, tropical semiúmido, com índice pluviométrico anual que varia de 1250 a 1500 mm com duas estações definidas pela distribuição das chuvas: estação chuvosa (primavera-verão) e estação seca (outono-inverno). A média anual possui pequena amplitude térmica, exceto em fenômenos de friagem, com temperatura média anual de $26,8^{\circ} \mathrm{C}$, e média das máximas de $42^{\circ} \mathrm{C}$ e médias das mínimas de $15^{\circ} \mathrm{C}$ (MAITELLI, 2005; FRANCO et al., 2013).

Os solos do Parque Massairo Okamura são do tipo Plintossolo Pétrico Concrecionário Distrófico típico e Latossolo vermelho-amarelo distrófico típico (GUARIM \& VILA NOVA, 2008).

Amostras dos solos do local, numa profundidade de 0 a $15 \mathrm{~cm}$, apresentaram para a área revegetada como classe textural franco-siltoso com $28,62 \%$ de areia, 1,47\% de argila e 69,91\% silte, matéria orgânica 2,38\%, carbono orgânico total $1,38 \%$ e $\mathrm{pH}$ em $\mathrm{KCl}$ 6,7. Para a área antropizada caracterizou-se como classe textural franco-arenoso com 51,13\% de areia, 1,47 \% de argila 47,4 \% de silte, matéria orgânica 1,24 \%, carbono orgânico total $0,72 \%$ e pH em $\mathrm{KCl} 4,3$. Os valores de densidade de partículas dos solos apresentaram números médios de $3,57 \mathrm{~g} \mathrm{~cm}^{-3}$, podendo ser justificado pelos baixos teores de matéria orgânica no solo que reduzem esse indicador físico (PEDRALINO et al., 2013). 


\section{Coleta de dados}

O estudo foi realizado uma vez ao mês, durante 24 horas de exposição da armadilha de álcalis, no período de julho de 2012 a junho de 2013. O experimento foi conduzido em delineamento inteiramente casualizado com dois tratamentos (T1: área revegetada (bosque); T2: área antropizada) e dez repetições. Cada unidade experimental foi constituída de uma armadilha de álcalis, sendo uma testemunha ou branco por área.

Também foram medidas a temperatura do solo, ar e a umidade do solo. Os dados de precipitação foram obtidos no site do Instituto Nacional de Meteorologia - INMET.

\section{Metodologia}

A armadilha de álcalis baseia-se no método desenvolvido por Walter \& Haber (1957) e adaptada por Grisi (1978) e constituiu-se de recipientes plásticos contendo $10 \mathrm{~mL}$ de solução aquosa de $\mathrm{KOH} 0,5 \mathrm{~N}$, para a captação de $\mathrm{CO}_{2}$ do solo. Estes potes destampados ficaram sobre suportes metálicos de $2 \mathrm{~cm}$ de altura. Sobre estes foram colocados baldes metálicos com $25,5 \mathrm{~cm}$ de diâmetro, cobrindo uma área de 510,69 cm² com as bordas devidamente enterradas no solo. O testemunho (branco), nas mesmas condições, teve 0 recipiente plástico fechado durante a coleta de $\mathrm{CO}_{2}$.

Após 24 horas de permanência das armadilhas de álcalis nas áreas, os baldes metálicos foram retirados, e os recipientes foram imediatamente fechados e levados ao laboratório de Química Analítica do IFMT-campus Cuiabá-Bela Vista para a análise química.

A quantificação do $\mathrm{CO}_{2}$ desprendido do solo e capturados pela solução de $\mathrm{KOH}$ contida nos recipientes, foi feita mediante titulação do $\mathrm{KOH}$ remanescente nos recipientes, com uma solução de $\mathrm{HCl}$ a $0,1 \mathrm{~N}$, e os pontos de viragem observados para os indicadores fenolftaleína a $5 \%$ e posteriormente metil-orange a $5 \%$.

A massa de $\mathrm{CO}_{2}$ desprendido por unidade de área e tempo $\left(\mathrm{mg} \mathrm{m}^{-2} \mathrm{~h}^{-1}\right)$, foi calculada considerando a massa de $\mathrm{CO}_{2}$ total desprendida no período de permanência debaixo da campânula e sua área de abrangência, conforme Equação 1. 
Em que, VB é a diferença dos volumes do ácido clorídrico gastos na titulação do branco com os dois indicadores; VA é a diferença dos volumes do ácido clorídrico gasto na titulação da amostra com os dois indicadores; $\mathrm{NHCl}$ é a normalidade do ácido clorídrico $(0,1 \mathrm{~N})$; Eq $\mathrm{CO}_{2}$ é a equivalente grama do $\mathrm{CO}_{2}$ (22); A é a área de abrangência da campânula (104: transformação da área para $\mathrm{m}^{2}$ ); $T$ é o tempo de coleta em horas. $4 / 3$ é o fator que corrige o valor do efluxo de $\mathrm{CO}_{2}$ no solo que pelo método químico é subestimado em $25 \%$.

A temperatura do ar e do solo foram medidas com termômetro análgico e a umidade do solo pelo método gravimétrico.

Análise de dados

Os dados coletados foram submetidos à análise de variância. As análises médias foram realizadas nas duas áreas pelo Teste de Tukey a 1\% de probabilidade. Ademais, para verificar se houve correlação significativa entre a respiração do solo e os fatores abióticos foi utilizado o coeficiente de correlação de Pearson (r), utilizando-se o software SISVAR (FERREIRA, 2010).

\section{RESULTADOS E DISCUSSÃO}

A média anual da respiração do solo no bosque e na área antropizada foi 130,6 e $86,7 \mathrm{mgCO}_{2} \mathrm{~m}^{-2} \mathrm{~h}^{-1}$, respectivamente. A respiração do solo no bosque foi maior que na antropizada ao longo do ano, em todos os meses, sendo na média anual, 1,5 vezes maior, conforme Figura 2 .

Figura 2. Média da respiração do solo $\left(\mathrm{mgCO}_{2} \mathrm{~m}^{-2} \mathrm{~h}^{-1}\right)$ no bosque e na área antropizada entre julho de 2012 a junho de 2013. 


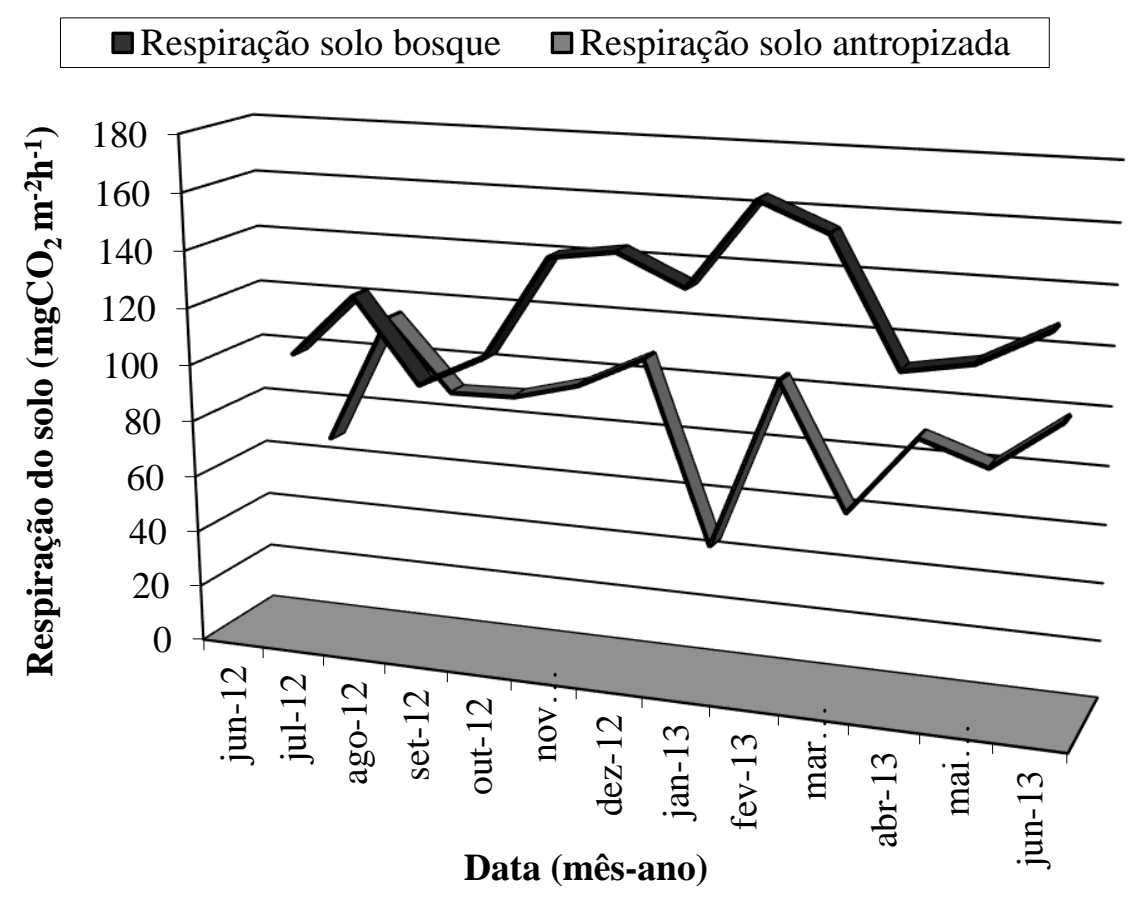

Houve efeito significativo entre os tratamentos em todos os meses avaliados, com exceção de setembro/2012, apresentados na Tabela 1.

No bosque, houve correlação significativa entre a respiração do solo e temperatura do solo $\left(r=-0,54^{\star}\right)$, entre a respiração do solo e a umidade do solo $\left(r=0,67^{\star}\right)$ e entre a respiração do solo e a precipitação $\left(r=0,62^{*}\right)$. Na área antropizada, as correlações entre a respiração do solo e os fatores abióticos não foram significativas.

Tabela 1. Comparação das médias mensais da respiração do solo $\left(\mathrm{mgCO}_{2} \mathrm{~m}^{-2} \mathrm{~h}^{-1}\right)$ do bosque e área antropizada entre julho de 2012 e junho de 2013 (CV é o coeficiente de variação).

\begin{tabular}{cccc}
\hline \multirow{2}{*}{ Mês/ano } & \multicolumn{2}{c}{ Respiração solo $\left(\mathrm{mgCO}_{2} \mathrm{~m}^{-2} \mathrm{~h}^{-1}\right)$} & \multirow{2}{*}{ CV $(\%)$} \\
\cline { 2 - 3 } & Bosque & Área antropizada & \\
\hline Julho/12 & $104,93 \mathrm{a}$ & $68,51 \mathrm{~b}$ & 12,54 \\
Agosto/12 & $127,00 \mathrm{a}$ & $114,12 \mathrm{~b}$ & 7,03 \\
Setembro/12 & $98,07 \mathrm{a}$ & $89,38 \mathrm{a}$ & 9,66 \\
Outubro/12 & $109,19 \mathrm{a}$ & $89,92 \mathrm{~b}$ & 8,86 \\
Novembro/12 & $144,87 \mathrm{a}$ & $95,94 \mathrm{~b}$ & 10,05 \\
Dezembro/12 & $148,28 \mathrm{a}$ & $107,1 \mathrm{~b}$ & 23,83 \\
Janeiro/13 & $138,03 \mathrm{a}$ & $43,86 \mathrm{~b}$ & 10,65 \\
Fevereiro/13 & $167,95 \mathrm{a}$ & $103,81 \mathrm{~b}$ & 10,52 \\
Março/13 & $158,75 \mathrm{a}$ & $60,52 \mathrm{~b}$ & 20,42 \\
Abril/13 & $116,58 \mathrm{a}$ & $88,39 \mathrm{~b}$ & 7,93 \\
Maio/13 & $120,83 \mathrm{a}$ & $80,57 \mathrm{~b}$ & 8,75 \\
Junho/13 & $133,13 \mathrm{a}$ & $97,91 \mathrm{~b}$ & 8,07 \\
\hline
\end{tabular}

Médias seguidas com a mesma letra minúsculas não diferem entre si, pelo teste de Tukey a $1 \%$ de probabilidade.

Revista Internacional de Ciências · v.5 - n.2 · jul./dez. 2015 
No bosque houve correlação significativa entre a respiração do solo e temperatura do solo $\left(r=-0,54^{*}\right)$, entre a respiração do solo e a umidade do solo $\left(r=0,67^{\star}\right)$ e entre a respiração do solo e a precipitação $\left(r=0,62^{\star}\right)$. Para a área antropizada, as correlações entre a respiração do solo e os fatores abióticos não foram significativas.

A disponibilidade de água para as reações bioquímicas relevantes dos microrganismos do solo aconteceu no local na época de maior precipitação (novembro de 2012 a abril de 2013), o que gerou maior efluxo de $\mathrm{CO}_{2}$ do solo, especialmente no bosque, conforme Figura 3. A flutuação sazonal no desenvolvimento microbiano é maior nas camadas superiores do solo, onde existem as maiores oscilações na umidade e na temperatura (CATTELANN \& VIDOR, 1990).

Figura 3. Precipitação acumulada mensal e umidade do solo no bosque e na área antropizada entre julho de 2012 e junho de 2013.

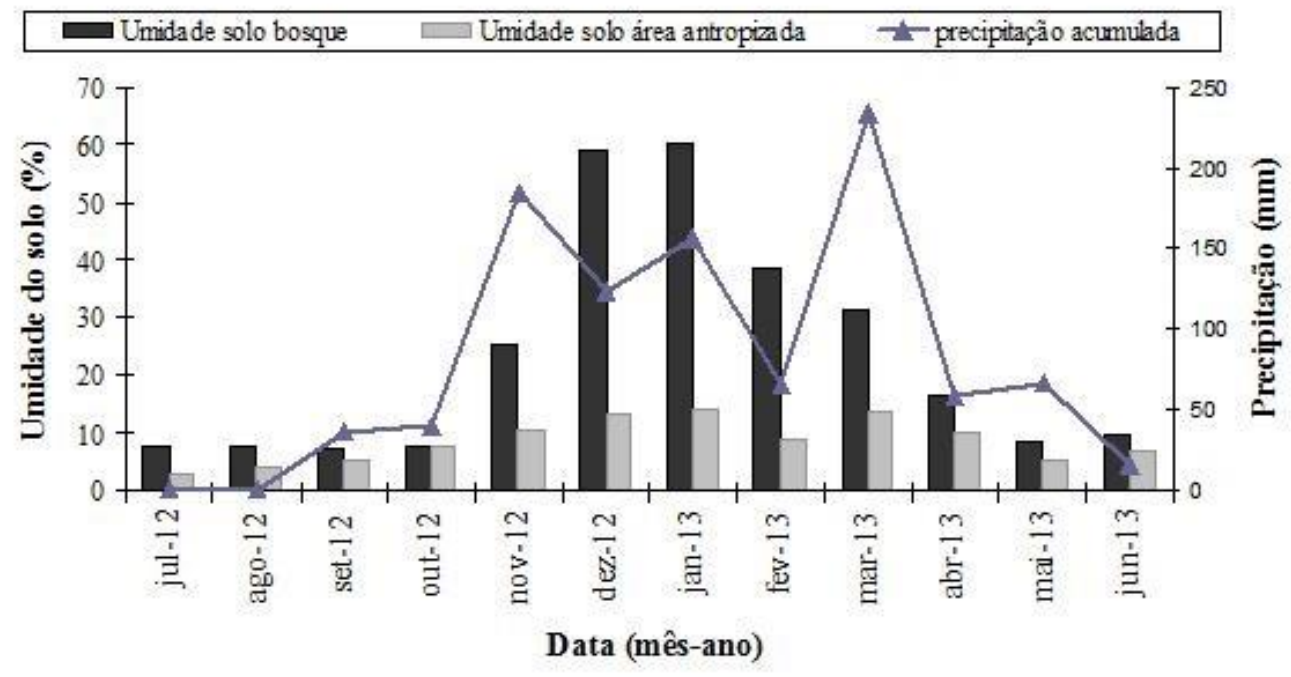

Na área antropizada, ao contrário, durante o pico da precipitação no local, houve uma diminuição da respiração do solo, indicando a importância da camada de serrapilheira que há no bosque. As interferências antrópicas, ocasionam perdas da matéria orgânica do solo e isso diminui a atividade da biomassa microbiana, uma vez que a matéria orgânica do solo atua como fonte de nutrientes e energia para a microbiota do solo (WILLIAMSON \& JOHNSON, 1994). Pedralino et al. (2013) inferiram ainda, que a baixa biomassa microbiana 
pode levar a um maior consumo de carbono para manter essa biomassa no solo, demonstrando estresse na população microbiana e, consequentemente, perda da qualidade do solo e isso é fundamentado, também, pelos baixos teores de carbono orgânico total nesse solo.

$\mathrm{Na}$ área antropizada Pedralino et al. (2013) encontraram baixo valor de saturação de bases, 49,75 \%, (V\%<50), enquanto para o bosque 83,04 \%. Isso se deve à intensa movimentação e intemperização sofrida nessa área e ao seu redor, o que interfere no transporte e na disponibilidade de nutrientes. Consideraram este solo distrófico, ou seja, se mostraram incapazes de disponibilizar nutrientes às plantas.

A vegetação é determinante para o estabelecimento da comunidade da fauna do solo. A qualidade e a quantidade do material decíduo podem afetar as populações da fauna do solo, resultando em mobilização diferencial dos nutrientes, com conseqüências para a ciclagem de nutrientes e a fertilidade do solo (WARREN \& ZOU, 2002). Assim, a diversidade da comunidade edáfica vai depender da diversidade vegetal, considerando que esta comunidade tem como habitat principal a camada de serrapilheira destes ecossistemas (BARROS et al., 2002). Os fatores climáticos mais atuantes durante o processo de decomposição da matéria orgânica, segundo Singh \& Gupta (1977), são a temperatura e a umidade do solo e a precipitação pluviométrica. O clima quente e úmido acelera a atividade biológica do solo e, conseqüentemente, aumenta a velocidade de decomposição (SWIFT et al., 1979). Como taxa de respiração do solo é considerada um indicador dessa atividade microbiológica do solo, a produção do $\mathrm{CO}_{2}$ dentro do solo responde fortemente às variações dessas variáveis (FANG \& MONCRIEFF, 2001; SUBKE et al., 2004).

Em estudo realizado no bosque, houve uma produção média mensal de serrapilheira de $990,57 \mathrm{Kg} \mathrm{ha}^{-1}$ e o acúmulo médio mensal de $10.957,31 \mathrm{Kg} \mathrm{ha}^{-}$ 1. A composição média de serrapilheira produzida foi $43,98 \%$ de folhas; 23,05 $\%$ de galhos; $17,64 \%$ de sementes e 16,95 \% de outros e para a quantidade média acumulada resultou em 41,92 \% de folhas; 32,04 \% de galhos; 17,22 \% de sementes e 14,40 \% de outros (VALENTINI et al., 2014).

Importante ressaltar que a matéria orgânica do solo no bosque (2,38 \%) é praticamente o dobro da área antropizada (1,24\%). Essa matéria orgânica é importante não apenas por ser fonte de nutrientes, mas por atuar na agregação 
de partículas, conferindo ao solo condições favoráveis de arejamento e friabilidade, de aumentar a retenção de água em solos e ser responsável em grande parte pela capacidade de troca de cátions (RAIJ, 1981).

As temperaturas do ar e do solo no bosque foram menores do que na área antropizada (Figura 4). Cattelan \& Vidor (1990) observaram que, em sistemas com maior produção de biomassa vegetal e acúmulo de resíduos na superfície, o solo fica eficientemente protegido, ocorrendo uma diminuição das variações térmicas e hídricas.

Figura 4. Temperatura média mensal do ar e do solo no bosque e na área antropizada entre julho de 2012 e junho de 2013.

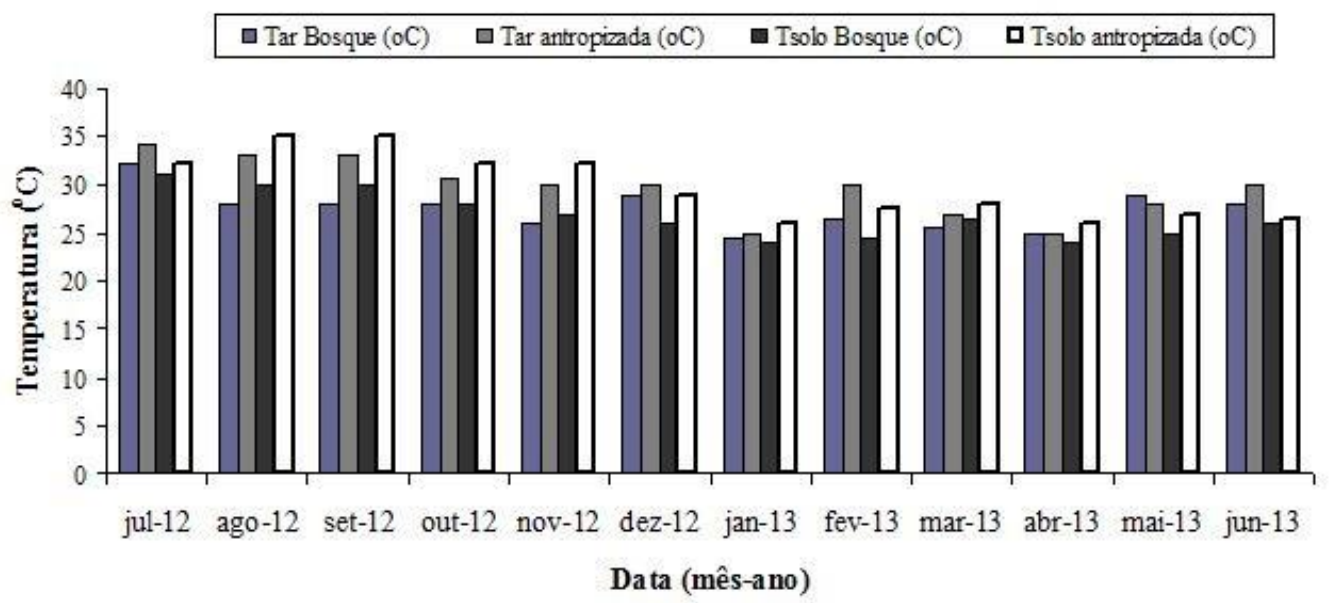

No bosque, a taxa de decomposição média da serapilheira (k) foi 1,004, que indiretamente representa a velocidade com que os nutrientes, ligados a ela, tornam-se disponíveis. O tempo médio de renovação da quantidade de serapilheira acumulada sobre o solo $(1 / k)$ foi 11,95 meses e o tempo médio necessário para o desaparecimento de 50 e $95 \%$ da serrapilheira foi, respectivamente, de 8,28 meses e 35,84 meses (VALENTINI et al., 2014). Estes valores indicam rápida ciclagem de nutrientes da vegetação.

No experimento com bolsas de decomposição (litter bags) com a principal espécie monodominante do bosque, a Jacaranda cuspidifólia, houve diminuição do material depositado após o início da precipitação indicando maior taxa de decomposição pelos microrganismos presentes no solo, que com a umidade encontram condições favoráveis para maior degradação da matéria orgânica depositada. Observou-se ainda, que o material depositado diminuiu 
consideravelmente nos meses com maior precipitação no local entre os meses deste trabalho (VALENTINI, SANCHES \& FARIA, 2015). Essas observações corroboram com as maiores médias de respiração do solo no perídio chuvoso.

Com a alteração do habitat natural, como foi o caso da área antropizada, muitas espécies abandonam o ambiente e inúmeros indivíduos ou espécies morrem ou são até extintas, até que um novo equilíbrio se estabeleça (THOMAZINI \& THOMAZINI, 2000). Portanto, as intervenções na cobertura vegetal promovem alterações na densidade e na diversidade da fauna do solo, gerando o desaparecimento de determinados grupos em função da interdependência e da fauna edáfica e da diversidade de recursos, indicando a ocorrência de problemas ambientais (BROWN, 2001).

É importante ressaltar que com esse estudo, considerando o bosque, foi possível usar todos os três principais indicadores adotados por Anderson \& Swift (1983), para medir a decomposição da camada de serapilheira que são: a respiração do solo; o valor k-relacionado à quantidade de material que cai do dossel (litterfall) e a que está depositada sobre o solo (litterpool); e as avaliações diretas através de medidas de perda de massa em sacos de tela para o estudo da decomposição (litterbags).

Os valores apresentados ratificam que uso inadequado do solo aliado a práticas não conservacionistas permite que o carbono estocado no solo na forma orgânica e microbiana, como também na forma de biomassa vegetal, seja remobilizado para a atmosfera (De-POLLI \& PIMENTEL, 2005). Daí a importância de se revegetar áreas antropizadas, visto que com o tempo o estoque de carbono no solo e ciclagem de nutrientes serão restabelecidos.

\section{CONCLUSÕES}

- A respiração do solo no bosque foi maior que na área antropizada ao longo dos meses de estudo, sendo na média, 1,5 vezes maior.

- A respiração do solo no bosque foi influenciada especialmente pela temperatura e umidade do solo e precipitação.

- A respiração do solo é um bioindicador para quantificar as respostas de recuperação de áreas degradadas e foi eficaz nas medições realizadas 
nesse estudo ao se comparar uma área revegetada e uma área antropizada no mesmo local.

\section{REFERÊNCIAS}

ANDERSON, J.M.; SWIFT, M.J. Decomposition in tropical forests. In: SUTTON, S.L.; WHITMORE, T.C.; CHADWICK, A.C. (Eds.) Tropical rain forest: ecology and management. London: Blackwell Scientific, 1983. p.287-309.

BARROS, E.; PASHANASI B.; CONSTANTINO R.; LAVELLE, P. Effects of landuse system on the soil macrofauna in western Brazilian Amazonia. Biology \& Fertility Soil, v.35, p. 338-347, 2002.

BROWN, G.G. Diversidade e função da macrofauna no sistema edáfico agrícola. In: Congresso Brasileiro de Ciência do solo, 28, 2001, Londrina. Anais...Londrina: Sociedade Brasileira de Ciência do solo, 2001. p.56.

CAMPOS, N. B.; SILVA, E.G. Projeto de recuperação de área degradada na reserva ecológica "Massairo Okamura" em Cuiabá-MT. 1998.18p.

CATTELAN, A.J.; VIDOR, C. Flutuação na biomassa, atividade e população microbiana do solo, em função de variações ambientais. Revista Brasileira de Ciência do Solo, 14:133-142, 1990.

DAVIDSON, E.A.; SAVAGE, K.; VERCHOT, L.V.; NAVARRO, R. Mimimizing artifacts and biases in chamber-based measurements of soil respiration. Agricultural and Forest Meteorology, v.113, p.21-37, 2002.

DE-POLLI, H.; PIMENTEL, M.S. Indicadores de qualidade do solo. In: AQUINO, A.M.; ASSIS, R.L. (Ed.). Processos biológicos no sistema solo-planta: ferramentas para uma agricultura sustentável. Brasília: Embrapa-SCT, 2005. p.17-28.

FANG, C.; MONCCRIEFF, J. B. The dependence of soil efflux on temperature. Soil Biology \& Biochemistry, v. 33. p. 155-165. 2001. 
FEIGL, B.J., STEUDLER, P.A., CERRI, C.C. Effects of pasture introduction on soil $\mathrm{CO}_{2}$ emissions during the dry season in the state of Rondônia, Brazil. Biogeochemistry, v.31, p. 1-14, 1995.

FERREIRA, D. F. SISVAR - Sistema de análise de variância. Versão 5.3. Lavras: UFLA, 2010.

FRANCO, F. M.; NOGUEIRA, M. C. J. A.; PINTO JÚNIOR, O. B.; BIUDES, M. S. NOGUEIRA, J. N. Traçado urbano e sua influência no microclima: Um estudo de caso em centro histórico. Revista Eletrônica em Gestão, Educação e Tecnologia Ambiental - REGET, v.9, n.9, p.1916-1931, 2013.

GRISI, B. M. Método químico de medição da respiração edáfica: alguns aspectos técnicos. Ciência e Cultura, v.30, n.1, p.82-88, 1978.

GROFFMAN, P.M.; McDOWELL, W.H.; MYERS, J.C. \&MERRIAM, J.L.Soil microbial biomass and activity in tropical riparian forests. Soil Biology \& Biochemistry, v.33, p.1339-1348, 2001.

GUARIM, V. L. M. S; VILANOVA, S. R. F. (Org.). Estudo do Parque Massairo Okamura. In: Parques urbanos de Cuiabá, Mato Grosso: Mãe Bonifácia e Massairo Okamura. Cuiabá: Entrelinhas/Edufmt, 2008. p. 71-77.

HOUGHTON, J. T. (Ed.). Climate change 2001: Climate change 2001 the scientific basis. Cambridge: Cambridge University Press: IPCC, 2001. 881 p.

MAITELLI, G. T. Interações atmosfera-superfície: o clima. In: MORENO, G; TEREZA HIGA, T.C.S; MAITELLI, G.T. (Org.). Geografia de Mato Grosso Território, Sociedade, Ambiente. Cuiabá: Entrelinhas, p. 238-249, 2005.

MANOLIADIS, O.G. Development of ecological indicators - a methodological framework using compromise programming. Ecological Indicators, v. 2, p.169176, 2002.

MORAES, L. F. D.; CAMPELLO, E. F. C.; FRANCO, A. A. Restauração florestal: do diagnóstico de degradação ao uso de indicadores ecológico para o monitoramento das ações. Oecologia Australis, v.14, n.2, p. 437-451, 2010.

MORAIS, R. F; VALENTINI, C. M. A.; CORRÊA, B. M. B. Composição florística e características estruturais e ecológicas da vegetação de um fragmento revegetado de Cerrado em área urbana no município de Cuiabá-MT. In:

Revista Internacional de Ciências · v.5 - n.2 · jul./dez. 2015 
Múltiplos olhares sobre a biodiversidade. Volume III. Pasa, M. C. (org) Paco Editorial, 2014. p. 185-204.

MOREIRA, M. M. 52 f. Estoque de carbono e nitrogênio em áreas de vegetação nativa e antropizada no município de Irecê. Dissertação (Mestrado em solos e qualidade de ecossitemas) Universidade Federal do Recôncavo da Bahia, Centro de Ciências Agrárias, Ambientais e Biológicas, 2013.

NORMAN, J. M. KURCHARIK, C. J.; GROWER, S. T.; BALDOCCHI, D. D.; CRILL, P. M.; RAYMENT, M.; SAVAGE, K.; STRIEGL, R. G. A comparasion of six methods for measuring soil-surface carbon dioxide fluxes. Journal of Geophysical Research, v. 102, p. 28771-28777. 1997.

PARKIN, T.B., DORAN, J.W., FRANCO-VIZCAÍNO, E. Field and Laboratory Tests of Soil Respiration. In: DORAN, J.W. et al. Methods for assessing soil quality. Madison: Soil Science Society of America, 1996. p.231-245.

PEDRALINO, F. O. ; BARBOSA, B. S.; CABRAL, I. F.; SOUZA, L. A. C.; CORINGA, E. A. O. Indicadores ambientais de solos do Instituto Federal de Mato Grosso, campus Cuiabá-Bela Vista. Anais... IV Congresso Brasileiro de Gestão Ambiental Salvador/BA - 25 a 28/11/2013, pag. 1-5.

POST, W. M.; KWON, K. C. Soil Carbon sequestration and land-use change: Processes and potential. Global Change Biology, v.6, p.317-327, 2000.

RAIJ, B. Van. Avaliação da fertilidade do solo. Instituto Agronômico do Estado de São Paulo. Campinas-SP, 1981. 2 ed. 142 p.

SILVA, R. B.; SANTOS, A. C.; BATISTA, R. B. Respiração edáfica como indicativo da qualidade do solo em três agrossistemas. Enciclopédia Biosfera, v. 6, n. 11, p. $1-15,2010$.

SINGH, J. S.; GUPTA, S. R. Plant decomposition and soil respiration in terrestrial ecosystems. Botanical Review, v. 43, p. 449-528, 1977.

SUBKE, J. A.; INGLIMA, I.; PERESSOTTI, A.; VEDOVE, G. D.;COTRUFO, M. $\mathrm{F}$. A new technique to measure soil $\mathrm{CO}_{2}$ efflux at constant $\mathrm{CO}_{2}$ concentration. Soil Biology \& Biochemistry, v.36. p. 1013-1015, 2004.

SWIFT, M.J., HEAL, O.W., ANDERSON, J.M. Decomposition in Terrestrial Ecosystems. Blackwell Scientific Publications, Oxford. 1979. 372p. 
THOMAZINI, M.J., THOMAZINI, A.P.B.W. Levantamento de insetos e análise entomofaunística em floresta, capoeira e pastagem no sudeste acreano. Rio Branco: Embrapa Acre, 2002. 41p. (Embrapa Acre. Boletim de Pesquisa e Desenvolvimento; n.35).

VALENTINI, C. M. A.; SANCHES, L., FARIA, R. A. P. G. Decomposição das folhas de Jacarandá cuspidifolia Mart. em bosque revegetado em Cuiabá, Mato Grosso.In: Múltiplos olhares sobre a biodiversidade. Volume IV. Pasa, M. C. (org) Paco Editorial, 2015. in press

VALENTINI, C.M.A; SOARES, G. S. ; SANTANA, R. A.; GUIMARÂES, A. F. S.; SILVA, A. H. B. Produção, acúmulo e decomposição de serapilheira em uma área revegetada do Parque Estadual Massairo Okamura em Mato Grosso. Revista Holos, v.5, ano.30; p. 211-221, 2014.

VIEIRA, G.; SANQUETTA, C. R.; KLÜPPEL, M. L. W.; BARBEIRO, L. S. S. Teores de carbono em espécies vegetais da Caatinga e do Cerrado. Revista Acadêmica Ciência Agrária Ambiental, v.7, p.145-155, 2009.

WALTER, H.; HABER, W. Uber die Intensitat der Bodenatmung mit Bemerkungen zu den Lundegardhschen. Werten. Ber. Dtsch. Bot. Ges. 70: 275- 282. 1957.

WARREN, M.W.; ZOU, X. Soil macrofauna and litter nutrients in three tropical tree plantations on a disturbed site in Puerto Rico. Forest Ecology and Management, v.170, p.161-171, 2002.

WILLIAMSON, J.C.; JOHNSON, D.B. Conservation of mineral nitrogen in restored soils at opencast coal mine sites: II The effects of inhibition of nitrification and organic amendmensts on nitrogen losses and soil microbial biomass. European Journal of Soil Science, v. 45, p.319-326, 1994. 


\section{AGRADECIMENTOS}

Ás bolsitas PIBIC CNPq/IFMT- Edital № 015/2012 IFMT, Maressa Bulhões dos Santos e Tayse Naiara Valuz Coelho, pela colaboração e dedicação nos trabalhos de campo e laboratório, e ao diretor de administração e planejamento do IFMT-campus Cuiabá-Bela Vista, Reinaldo Barbosa, por todo apoio para a execução da pesquisa.

Recebido:12/11/2015

Aprovado:07/12/2015 